\title{
Establishment and Research on Training Plan of Materials Science and Engineering which Adapted to the Social Demand - Kunming University of Science and Technology
}

\author{
Jun Li ,Kunyu Zhao, Zhidong Li, Dong Ye \\ - $\quad$ Faculty of Material Science and Engineering \\ - Kunming University of Science and Technology \\ - Kunming, China \\ • ljwj981@126.com, kyzhaoy@yahoo.com.cn, leezd@126.com,nina8117@163.com
}

\begin{abstract}
- Abstract - The progress and development of social civilization and economic will promote the advantage of materials science and engineering, while, it will put forward the corresponding requirements for talents. As the cradle of training talents, universities, in making talent cultivation plan and scheme, must follow the social demand. The construction of curriculum system should ensure that personnel training knowledge structure must adapt to social requirements. The curriculum should reflect the features of the development of the material science. The arrangement of teaching content should keep pace with the development of material science dynamics. The practical teaching content and arrangement should match with training goal.
\end{abstract}

Keywords-materials science and engineering; training program; social demand; curriculum system; practical teaching

\section{INTRODUCTION}

The concept of Materials science and engineering originated in Europe and the United States. Throughout the entire development course, in 1860s, metal material is given priority to; after the 1940s, material foundation theory and non-metallic materials course came into the classroom; after the 1980s, in order to adapt to the needs of society, materials science and engineering was classified as first level discipline $^{[1]}$. But in our country, the development of materials science is relatively late. At the end of the twentieth century, based on the integration of the original disciplines, such as heat treatment on metal materials, corrosion protection, pressure processing of non-ferrous metal and its alloy, powder metallurgy and high polymer materials, materials science and engineering had formed ${ }^{[2]}$. Whether at home or abroad, cultivation and education of talent are developed from professional training into disciplines, from professional education into subject education. To do so is to adapt to the social economic and industrial demand, and the new materials science and technology rapid development, in that case the corresponding inter-disciplinary talent was come up and widely accepted ${ }^{[3]}$.

At present, characteristics of materials science and engineering are subjective, crossed, new-branch discipline constantly emerging, and interdisciplinary subject emerge in endlessly, therefore, relatively the original professional training and education haven't met the requirements of the modern material science yet ${ }^{[4]}$. The functions of university were traditional talents training, scientific research, after that to serve the society, and then to put forward new inheriting civilization. Nowadays, the role of university in society is becoming more and more important, but the foundation of talents training will always not be moved. The future development of materials science and engineering must be foudation integrated, materials science and engineering mutually merged, multidisciplinary and interdisciplinary developed and research progressed rapidly. Looking back to history, every time when new materials appeared it would play epoch-making role to the social civilization and the progress of economy. Whereas, in the modern society, breakthroughs and development of the high-tech have a close relationship with the appearance of new materials technology ${ }^{[3]}$. The new material technology has become a very important symbol to the national industrial level and technical ability. Combined with characteristics of material science and engineering and functions of university, to establish cultivation plan for the talents who meet the social needs and the characteristics of material science development in colleges and universities, become the inevitable trend and choice.

\section{EDUCATIONAL GOAL}

The professional training aims to cultivate high-quality talents, who adapt to the construction of socialism with Chinese characteristics and the needs of the market economy, develop morally, intellectually and physically; has the scientific research innovation quality and engineering technology development ability, and with a solid theoretical foundation and professional knowledge; could engage in the design, research, preparation, processing, analysis, inspection, quality control, management, and other aspects of materials science and engineering and the related fields.

\section{CURRICULUM SYSTEM DESIGN}

Curriculum construction and the guiding ideology settings based on the principle of "engineering is given priority to, take account on science at the same time, mutual penetration and cross". The contents of the courses complyed with the 
principle of "based on the foundation, keep features, follow the development, and take market as the guide". Because of the above two points on curriculum and course content arrangement and update, 4 classes have been set up in the curriculum system. The total credits is 200, among this, Theory teaching is occupied $73.75 \%$, practice teaching accounted for $26.25 \%$.

- first class courses: science and engineering platform as basic course, the study of basic course, core course and general course is given priority to, credit accounted for $43.87 \%$;

- secondary courses: discipline foundation course, set Materials Science Foundation and Materials Engineering Foundation as professional basic courses, matching with similar and related basic theory courses, credit accounted for $38.07 \%$;

- tertiary courses: module courses, according to the different modules establish different course, take professional quality education targeted, credit accounted for $10.32 \%$;

- fourth class courses: professional elective courses, mainly for the relevant professional and areas of professional elective courses, credit accounted for 7.74\%.

Discipline platform class includes the humanities, law, computer, economy, mathematics, physics, ect. General courses emphasize on characteristics, basic courses reflect the content of the corresponding cohesion and matching, and professional courses follow the frontier disciplines, occupying the commanding heights, carrying out scientific research teaching integration and scientific research merged into teaching. Take the market as the guidance, considering constantly the situation change and the demands of the society for talents, setting ability and quality education as the goal, design the teaching content.

\section{A. Module Settings}

The professional module settings are agile and gaining a firm foundation, responsing country demand, finding features and following the market. However, in the new training program, taking the market as the guidance, in close connection with the demand of the country, the development of the industry and international materials science and engineering development dynamic, module is carries on the corresponding adjustment. The original training modules mainly are metal materials, pressure processing, powder metallurgy, functional materials and inorganic nonmetallic materials engineering. Then modules changed to metal materials, pressure processing, powder metallurgy, rare metal materials and inorganic nonmetallic materials engineering, while functional materials as the new major.

For the professional module, metal material has been the foudation of materials science and engineering to our school, and is the root of the professional, which cultivated the largest number of talents, and won higher population for employers; In 2010, functional materials module successfully became a national strategy of emerging professional - professional construction of functional materials made it recruit students independently, and set training program singly; Setting of inorganic nonmetallic materials engineering is agile, mainly based on talents' market demand, when the market need, it could open at any time; The new opened rare metal materials module, is mainly combined with local regional advantages, matching the discipline construction, talent demand, and other comprehensive consideration. It not only can realize graduate employment shunt, but also reserve talents for long-term development of rare metal materials. Howecer, in the nationwide, there is hardly a separate course related to rare metal material direction in universities, so it is the characteristics to our faculty of materials science and engineering and also an important action in building up the bridgehead of discipline construction.

\section{B. Module courses setting}

The courses setting should adapt to the discipline development rules, by doing this a reasonable knowledge structure can be built $[5,6]$. The original training program emphasized and paid attention to the foundation. But after a few years practice, feedback from employers shows that students have been trained potential, basic solid, and became universal talents; but when assigned to specific post, they appeared "only see, won't do" characteristics, thus, materials science and engineering rethinking their own training program to adjust the curriculum and course content. Metal materials, powder metallurgy and pressure processing module course are fine-tuning, rare metal materials remain unchanged, and inorganic nonmetallic material module expanded to the whole industry. Years of talent cultivation practice proves that the original knowledge system and structure could ensure students' comprehensive qualities, but to adapt to the development of society, industry and enterprise, and to promote the quality of talents, professional knowledge and ability, each module courses and content have been adjusted.

In metal material engineering module, materials science and materials performance are determined clearly as metal material science and metal material performance, and the adjustment is mainly on the content. Heat treatment process is changed to heat treatment principle, process and equipments, owning to students' comprehension to basic principle of solid basic knowledge is not enough and the concept of theory fuzzy is not strong; Alloy smelting is taken iron and steel and non-ferrous metal smelting instead, it is mainly for students employed in steel and non-ferrous industry. At the same time, it is taught seperately with rare metals module, in order to achieve targeted, goal-oriented and contents condensed purpose. Delete the metal plastic forming process and add the metal corrosion and protection, mainly considering the metal material application requirements continuously improve, and the anti-corrosion 
requirements under the environment of are becoming more and more important.

In powder metallurgy module, materials science and materials performance have been changed to metal material science and metal material performance, considering the knowledge and theory are needed in the processes of powder metallurgy components' following treatment, evaluation and test.The principle and process of powder metallurgy has been divided into powder metallurgy principle and powder metallurgy process and equipment. Aims at the original course credits is not enough, related important theory and technology content cannot be understood perfectly, consequently, a single class, which increase the credits of theory and process, meanwhile the principle and process are taught seperately; Delete powder materials and engineering course, basically the content of metallurgical powder is merged into powder metallurgy and equipment, and deleted contents focus on nonmetal powder; as well as keep die design course.

In pressure process module, material science and material performance are further refined into metal material science and metal material performance; keep two courses-pressure processing equipment and plant design and metal plastic forming process retained, and increase groove and die design course. In original curriculum settings, mould design is just an elective course, but according to feedbancks from employers, the previous graduates showed solid knowledge background without doubt. Nevertheless, their professional knowledge was weak. So, for the process of shaped metal material, groove and die designing is a vital step, that is to say, put groove and mould design as a compulsory course module is necessary.

Module curriculum setting of precious metal materials began to be considered in 2009. There is no graduates till now, while this curriculum content mainly focus on basic knowledge. Yunnan province as a metal reserves abundant province in China, has put SINO-PLATINUM METALS co. as the industry leader and on that basis deep processing has also made great progress. But in recent years, problems on machining technology and process have been overcome, and applications of precious metals is more and more taken seriously, then the demand of successive industry talents grows increasingly. Therefore, in combination with regional advantages and local characteristics, the content of courses mainly target at chemical and physical properties, processing and applications of precious metal materials.

Compared to the original curriculum, inorganic nonmetallic material module is broadened. The original curriculum mainly concerned on cement, while current curriculum settings include silicate materials such as cement, glass, ceramics for daily use and building materials.

\section{PRACTICAL TEACHING DESIGN}

For the characteristics of thick talents foundation and weak practice ability in the past, practical teaching credits is increasing in the new training plan, and credits for materials science and engineering major rises from original 33 to 52. The initiate course practice mainly retains the original practical teaching basis, thereby basic discipline experiment, engineering practice and innovative design could be added. Practical teaching is mainly divided into two categories as classroom experiment and extracurricular practice. Then classroom experiment is divided into professional and nonprofessional course, moreover non-professional experiment is arrange by participating college. And all professional experiment course mainly relys on materials science and engineering experimental teaching center, carrying out that experiment teaching and teaching mode management independently. Extracurricular practice mainly includes graduation design or thesis, three practices, course design, engineering training and all kinds of competition and activities which rely on the subjects of innovation platform.

\section{A. Teaching reform of in-class experiment}

In the experiment teaching system, aiming at student's different major, interest, ability and levels of knowledge structure, we set up four levels of experiment which contain basic, comprehensively designed, engineering practical and scientific research innovation.

- basic experiment teaching. The content includes preparation of material and machining experiment, material performance test and analysis experiment, modern material analytical methods and microstructure observation and analysis experiment, etc. Target to make experiment content meet experimental teaching outline, to deepen students' master of basic theory, knowledge and skills, to train students' preliminary practical and analysis ability and to motivate students' interest in study. With the combination of advanced laboratory equipments and homemade experimental apparatus, high quality foundation experiment teaching platform has been buildt.

- comprehensive and designing experiments. Contents include materials science and engineering comprehensive design experiment and computer simulation module. This module is based on basic experiment, and improve the experiment more difficulty and integrated. Aims to cultivate professional knowledge, integrated design and analysis ability to students.

- engineering practical experiments. Contents concentrate on combination with the engineering practice and practice research, focus on practical problems, moreover deepen application of knowledge of materials science and engineering. Aims to improve students' engineering actual problem solveing ability, develop their knowledge scope so as to increase employment competitive power.

- scientific innovation experiments. Concentrated on senior undergraduates, and experiment content including student graduation thesis (design), which students could choose experiment item, make 
experimental plan optionally, then do experiment independently under the guidance of teachers, finally summary analysis and come to a conclusion. Aims to provide students with a good experiment platform, improve the students' scientific research ability and cultivate the students' spirit and innovation ability.

\section{B. Extracurricular practice arrangement}

Allow students to participate in scientific research freely. Multidisciplinary platform provides abundant practical contents. Undergraduate students from junior could start to get into different research groups to participate in scientific research, which may improve students' professional quality education, and cultivate subjective initiative and practice ability, engineering consciousness and engineering ability, innovation consciousness and innovation ability as well. Relying on projects from academic teams and groups, the conception of making use of projects as students' science and technology innovation project and extracurricular academic innovation subject is put forward. It is benefit for training students who have spare capacity to learn comprehensively, and providing approach for cultivating innovative students.

\section{ACKNOWLEDGMENT}

This work was financially supported by the Scientific Education Discipline Project of Yunnan Province (GG09007).

\section{REFERENCES}

[1] M.C Flemings, R.W Cahn. Organization and Trend in Materials Science and Engineering Education in the US and Europe [J]. Acta Materialia, 2000,48(1), 371-383.

[2] Li Hengde, Zuo Tieyong .A Perspective of Materials Science and Engineering Education in China [J]. Materials Science and Engineering A, 1995,199(1), 9-14.

[3] M. C. Flemings. WHAT NEXT FOR DEPARTMENTS OF MATERIALS SCIENCE AND ENGINEERING[J]. Annu. Rev. Mater. Sci. 1999. 29:1-23.

[4] Kee Hyong Kim. Environmental reforms of material science education in the 21st century[J]. Materials Chemistry and Physics, 1999(61),14-17.

[5] Yael Kali, Rachel Levin-Peled, Yehudit Judy Dori. The role of design-principles in designing courses that promote collaborative learning in higher-education[J]. Computers in Human Behavior,2009(25), 1067-1078.

[6] Gustaf Ö stberg. Contextual perspectives on education in materials science and engineering[J]. Materials and Design 2005(26 ):313-319. 